R. História, São Paulo, n. 122, p. 97-115, jan/jul. 1990.

\title{
LUCIEN FEBVRE NO CAMINHO DAS MENTALIDADES
}

\author{
Ronald Raminelli ${ }^{1}$
}

RESUMO: O resgate de parte da obra de Lucien Febvre é o objetivo do presente ensaio, especialmente quando trata do tema mentalidades. Analisar-se-á basicamente dois livros: $O$ Problema da Descrença no Século XVI e Em torno do Heptaméron, obras da década de 1940 (período aqui privilegiado), procurar-se-á perceber os caminhos percorridos por Lucien Febvre para delinear a problemática, tentando encontrar a particularidade de seus estudos, que remetam à compreensão do "homem" e suas mentalidades. Torna-se importante pensar como estas questões foram tratadas no momento anterior aos estudos de Febvre, constatando quais foram os legados, os indícios que possibilitaram ao historiador introduzir a perspectiva mental no conhecimento histórico. Não quero, assim, dizer que Lucien Febvre tenha sido o pioneiro na história das mentalidades, mas destacar que o caminho trilhado por ele 6 singular, aspecto que será tratado ao longo do ensaio.

Abordar aspectos psicológicos em História não é nenhuma novidade. Nós mesmos, no Brasil, temos um conhecido historiador, que é exemplo típico de um estudioso de personagens históricos. Vale a pena citar Pedro Calmon, para ilustrar a maneira pela qual caracterizava psicologicamente um personagem:

"Continuava imperturbável, na sua tolerância mansa, de quem se não se espantava da ingratidão ou do esquecimento, indispensável à imperfeição humana." 2

1 Mestre em História pelo DH-FFLCH/USP.

2 CALMON, Pedro. A Vida de Pedro II, o Rei Filósofo. Rio de Janeiro: Bibl. do Exército, 1975. p. 282. 
O texto de Pedro Calmon e enfático na abordagem psicológica. Neste empreendimento, o indivíduo é visto em sí mesmo, não revelando o intrincado jogo social que banha o quotidiano do personagem. As explicações para um determinado comportamento nâo são formuladas a partir da sociedade, mas do homem em sí, através daquilo que ele possui de próprio. O ser, assim, é visto por intermédio do indivíduo e não através de uma complicada relação entre o particular e o social.

O tipo de descrição histórica exemplificado em Pedro Calmon é característico de historiadores do século XIX, preocupados com a questão da memória nacional e com a necessidade de resgatar e exaltar os homens que, pretensamente, possibilitaram a construção da identidade da nação. Ora, se não são os historiadores do século XIX o tema do artigo, no entanto é importante citá-los a fim de fazer um contraponto entre a abordagem do personagem histórico elaborada por Febvre e esta historiografia:

Nem mesmo pode-se afirmar que a descrição psicológica seja algo característico do século XIX. Segundo Georges Duby, a História, desde seus primórdios, sempre se preocupou com a descrição dos perfis psicológicos. Quando os acontecimentos deixaram de ser pensados pela ótica do mágico, muitos observadores passaram a explicá-los através do psicológico, tentando encontrar os motivos pelos quais um homem se sobressaía dos demais. A História, então se apresentava como um estudo dos comportamentos e das atitudes mentais, mesmo sendo feita de modo ingênuo ${ }^{3}$. Ao longo do tempo, percebeu-se que analisar um personagem histórico contemporâneo é um empreendimento simples, quando comparado ao estudo de uma época mais remota e logo, distante do mundo vivido pelo historiador. Ou melhor, o estudo de fatos recuados no tempo se torna perigoso à medida em que se afasta do presente do historiador (sobretudo quando se abordam as mentalidades). Neste caso, pode-se facilmente incorrer em erros de anacronia, ou melhor, atribuir a esses homens características que são peculiares à nossa época e, consequentemente, estranhas ao tempo estudado. Contudo, dificilmente seria possível captar o passado "in totum". Tal pretensão pertencia aos historiadores positivistas.

3 DUBY, George. Histoire des Mentalités. In: Samaran, C.. L'Histoire es ses Méthodes. Paris: Gallimard, 1961. (Encyclopédie de la Pléiade) 
Duby, ao relatar os antecendentes da história das mentalidades, comenta que a partir do século XVIII se iniciou um debate sobre atitudes psicológicas. Percebeu-se que, assim como os costumes e as maneiras de viver, os comportamentos psicológicos não eram os mesmos em todas as épocas. Neste período, concluiu-se que o homem havia deixado de viver um vida selvagem para construir uma civilização. Os intelectuais, assim, notaram a transformação sofrida pela sociedade humana ao longo dos séculos. Voltaire mesmo, em Essai sur les moeurs (Ensaio sobre os costumes), de 1756, tentou escrever uma história dos costumes humanos, mas năo teve continuidade. Depois de meados do século XIX, houve um lento desenvolvimento de uma história das sensibilidades com o aperfeiçoamento da História da Arte e Literatura. Entretanto, ainda segundo Duby, essas incursões na sensibilidade humana mostraram-se subjetivas e problemáticas. Outras tentativas, atuando sobre os fenômenos religiosos, levaram a um estudo da evolução da crença, mas o domínio da história "interior" foi dificultado pelo desenvolvimento insuficiente da Psicologia.

Quase no século XX, graças aos movimentos populares reivindicando participação política e a divulgação de concepções marxistas, tornou-se possível relativizar a tendência que tinham os historiadores de valorizar os grandes homens. Assim, os pensadores do social se voltaram para o grupo, deixando em segundo plano o indivíduo e passando, como diz Duby, a observar o coletivo e negligenciar os simples acontecimentos. Com essa perspectiva nasceu a Sociologia. A idéia de consciência coletiva surgiu com Durkheim, que iniciou estudos sobre atitudes mentais, não consideradas como particulares, mas comuns a todo um grupo. Tentava-se ligar as representações coletivas e as condutas individuais a uma realidade social, ou melhor, buscava-se explicar o coletivo e o particular, a partir da organização da sociedade - vinculação que se mostra evidente na obra de Lucien Febvre ${ }^{4}$.

Neste sentido, tenta-se perceber a construção da estrutura social a fim de buscar modelos explicativos; para isso é indispensável conhecer a gênese e as transformações ocorridas no seio desta organização. $\mathrm{O}$ recuo ao passado, e logo a formação e evolução das sociedades, nos remete ao conhecimento histórico; e

4 A obra de Durkheim é de extrema importância para a formulação do conceito de historia das mentalidades, sobretudo quando se trata de vertente inaugurada por L. Febvre. Há neste sociólogo a preocupação constante em distinguir o indivíduo da sociedade, dando prioridade à última. A sociedade em Durkheim dará os parâmetros ao indivíduo que os assimila de forma consciente. LÉVI-STRAUSS, C.. La Sociologia Francesa In: GURVITCH, G. e MOORE, W. E. (orgs.). La Sociologia del Siglo XX. Barcelona: Ateneo, 1965. v. 2, p.12/23. 
a história, então, afirma sua importância no empreendimento de pensar a estrutura social. Assim, na perspectiva de conhecer os mecanismos de formação da sociedade, deixa de ver o passado através do conhecimento do indivíduo e dos fatos, para se voltar às querelas do social - o que já tinha sido feito nos estudos de Marx. Entretanto, os historiadores, de maneira genérica, ainda levarâo mais algumas décadas para realmente se prender ao estudo das sociedades.

\section{LUCIEN FEBVRE}

Tentando enriquecer o debate da Sociologia, Febvre lança seu combate contra a história "événementièlle" (factual) e aponta o caminho para o que chama de história social, contando com o apoio de outros pensadores dos fenômenos humanos. O historiador une em sua proposta de trabalho dois fatores da maior relevância: por um lado, recupera o legado de intelectuais da virada do século, nomes como Sombart, Pirenne, Hauser, Henri Sée entre outros; por outro, busca inovar através do contato com várias disciplinas. Há influências do historismo alemão e particularmente do pensamento de Dilthey, além de uma forte presença das reflexões de Marcel Mauss. Interessante, entretanto, é notar que não há a menor menção a esses últimos nas obras de Febvre, sobretudo quando se trata de Mauss, que certamente teve participação na formulação de questôes existentes na obra do historiador (assunto que será tratado no final do ensaio e nas notas).

A junção entre psicologia, linguistica, etnologia e história foi a grande marca de Febvre. Sob influência da psicologia de Charles Blondel e Henri Wallon, Febvre lança o que se pode chamar de "manifesto da história das mentalidades", com a publicação, em 1938, do artigo intitulado "La Phsychologie et L'Histoire" no tomo VIII da Encyclopédie Française; depois em 1941, em Annales d'Histoire Social, um outro artigo: "La Sensibilité dans 1'Histoire", ambos encontrados nos Combates pela História. Os dois textos dão algumas pistas do que seria o método de se fazer história das mentalidades.

Guariba Neto ${ }^{5}$ nos fala da década de 1930 como um marco na produção historiográfica de Febvre. A revista Annales serviu, ao historiador, como um grande laboratório, onde foi possível estabelecer contatos com vários setores de 
pesquisa. Através de resenhas e comentários percebeu-se que esta época possibilitou-lhe uma série de reflexões referentes à investigação de um fundamento para o conhecimento em história. Propiciou uma construção metodológica, baseada na tentativa de uma interdisciplinariedade que beneficiasse a pesquisa. É também importante mencionar que no final da década de 1930, o historiador, certamente, estava trabalhando em seu livro mais conhecido, Le Problème de L'Incroyance..., publicado em 1942, obra onde se encontra um estudo sistematizado de mentalidades ${ }^{6}$.

No artigo de 1938, pode-se encontrar algumas indicações da publicação de 1942. Febvre o inicia perguntando qual seria o objeto de estudo do historiador: as massas e o indivíduo - responde ele. Contudo, trabalhar com as massas se torna muito complicado devido à falta de testemunhos; por isso, a história tem comumente fortes traços aristocráticos, se prendendo muitas vezes a personagens históricos e esquecendo de se ater ao social como um todo.

Em seu novo campo de estudo, Febvre nos fala da necessidade de se apegar aos conhecimentos científicos da função mental, da psicologia e utilizar em história a psicologia coletiva e a psicologia individual, tentando dois caminhos para a interpretação do real - o indivíduo e o social. A fim de explicitar esse contraponto, e sobretudo a posição do indivíduo na história, Febvre é levado a pensar na "obra histórica", ou melhor dizendo, na ação e no legado dos personagens históricos, que outrora eram o centro das atençôes dos historiadores, mas que, ao longo do tempo, tiveram sua ação relativizada. E é neste sentido, ação do indivíduo na história, que Febvre passou a conceber a "obra histórica" como fruto do social, reduzindo a autonomia do personagem histórico, antes tão exaltada.

"Numa palavra, tudo isso permite dizer que o indivíduo é sempre o que sua época e o seu meio social permitem" 7 .

É interessante ressaltar que a temática das principais obras do historiador volta-se sempre à questão do papel desempenhado pelo indivíduo no social. Seus

6 Livro considerado por vários historiadores como uma das primeiras obras em história das mentalidades "strito sensu". Entretanto, segundo Michel Vovelle, somente nos anos sessenta, com Robert Mandrou e George Duby, é que se desenvolve plenamente esse novo território do historiador. Vovelle, M. Ideologies et Mentalités. Paris: Maspero, 1985. p.9.

FEBVRE, L.. Combats pour l'Histoire. $2^{\text {a }}$ ed. Paris: A. Colin, 1965, p.221. 
RAMINELLI, Ronald. Lucien Febvre no caminho das mentalidades.

personagens, Lutero, Rabelais e Margarida de Navarra são analisados em suas características individuais, naquilo que os torna pessoas singulares em seus tempos. Entretanto, nunca deixa de compará-los ao meio que os cerca e os forma. A relação dialética entre indivíduo e sociedade é o tema central da obra "febvreana", onde o particular e o social são vistos em conjunto, buscando sempre complementariedade que possibilita a compreensão mais profunda do objeto em questão. Analisando o mesmo assunto, é importante refletir sobre as palavras de Mandrou:

"A psicologia coletiva de um grupo não é a soma das psicologias individuais dos participantes, o grupo não é uma simples adição de indivíduo. Os métodos de uma pesquisa não são imediatamente transportáveis ao grupo, nem à sociedade global" ${ }^{8}$.

Vê-se aí uma advertência, que não considero como uma crítica a Febvre, mas que é primordial para um historiador das mentalidades. O estudo do particular, seja ele a psicologia de um indivíduo, ou estudo das mentalidades de um indivíduo, grupo ou mesmo classe, não pode ser generalizado para a sociedade, como se a mesma fosse composta somente por esse particular. Generalização perigosa, que se deve sempre evitar.

No artigo de 1938, além de abordar a questão indivíduo-sociedade, Febvre comenta o problema da aplicação da psicologia à personagens e coletividades de outras épocas. Mostra o quanto pode ser anacrônico aplicar um método de análise _ que serviria para observar homens brancos da Europa Ocidental, que possuem uma determinada história - em comunidades de culturas, organização social e tempos diversos. O papel da psicologia seria, sobretudo, o de examinar o passado e perceber as diferenças entre nossos ancestrais e o homem contemporâneo, apreendendo os mecanismos de sua formação e a maneira pela qual o social se reproduz. Febvre diz ainda que não se pode utilizar a psicologia atual sem contar com a contribuição dos historiadores.

8 MANDROU, R. L'histoire des mentalités. In: artigo Histoire. In: Encyclopaedia Universalis. Paris, v. VIII, 1968. p. 437. A complementariedade entre psiquismo individual e a estrutura social, referida a pouco por Febvre, é mais uma contribuiçẩo de M. Mauss, que possibilitou a interdiciplinariedade, sobretudo entre etnologia (história) e psicologia; interação que se torna possível com a introdução da noção de inconsciente. 
A absorção do legado da psicologia na obra de Febvre é muito discutível; não há indícios maiores de emprego de categorias ou conceitos da psicologia na investigação dos personagens históricos. Ao analisar o indivíduo, Febvre não o faz sob um prisma psicológico, mas a partir da elaboração filosófica da "obra-histórica" em questão. Assim, há uma insistente discussão filosófica, sobretudo teológica, das obras de Rabelais e Marguerite. O historiador enveredou pela psicologia, a fim de perceber a relação indivíduo e sociedade, mas não para empregar no passado um conceito de psicologia. A sociologia e a filosofia, sim, ofereceram-lhe maiores contribuições do que a tão exaltada psicologia de Henri Wallon e Charles Blondel.

Neste sentido, vale ressaltar a diferença entre o estudo psicológico e a história das mentalidades. Não é explicitado por Febvre, mas é muito fácil de perceber quando se lê um livro sobre mentalidades. A psicologia, sobretudo antes de Freud, vê como determinante na ação dos indivíduos o biológico, enquanto na história das mentalidades o indivíduo é sempre um produto do social e especialmente no caso de Febvre, do embate entre a particularidade de cada homem e sua sociedade. Eis, então, uma das possíveis razões da restrita utilização por Febvre da contribuição da psicologia.

O outro artigo, entitulado "La Sensibilité et L'Histoire" se volta para o estudo das sensibilidades. Sua definição nos leva à vida afetiva e ao que temos de mais subjetivo. Entretanto, não podemos pensá-la como simples autonomia de um indivíduo em relação ao mundo exterior. Nasce em face da relação entre os homens, ou melhor da vida coletiva. A vida em comum possibilita a formação de um sistema de iniciações interindividuais que se diversifica segundo as circustâncias, além de ser enriquecido pelas reações e sensibilidades de cada um. O sistema emocional, mantido e regulado pelo grupo, torna-se o elemento de coesão entre os homens. A vida é regida por esse amálgama de emoções, que concede ao grupo poder e segurança. Assim, se justifica a constituição de um sistema de emoções, que logo se transforma em uma instituição. Vemos aí a gênese da cultura, da tradição e logo da atividade intelectual ${ }^{9}$.

"A atividade intelectual supõe a vida social. Seus instrumentos indispensáveis (em primeiro lugar a linguagem) implicam,

Mais uma vez é patente a influência velada de Durkheim. 
RAMINELLI, Ronald. Lucien Febvre no caminho das mentalidades.

com efeito, na existência do agrupamento humano, no qual eles são necessariamente elaborados - já que o seu objetivo é operar o entrosamento dos participantes de um mesmo grupo" ${ }^{10}$.

Foram comentados dois dos artigos de Febvre que abordam o tema das mentalidades; contudo existem outros que enumerarei em seguida: Sorcellerie, sottise ou révolution mentale? (Bruxaria, bobagem ou revolução mental). In Annales E.S.C., 1948 -artigo que serviu como base à elaboração da obra máxima de Robert Mandrou; De l'à peu près à la précision (Do mais ou menos à precisão). In: Annales E.S.C., 1950; Histoire de Sentiments. La terreur. In: Annales E.S.C., 1951.

\section{RABELAIS E MARGARIDA}

O Problema da Descrença no Século XVI. A religião de Rabelais (Paris, 1942) e Em torno do Heptaméron. Amor Sagrado. Amor Profano(Paris 1944), são obras onde a temática do indivíduo/sociedade é uma constante. A partir de Rabelais e Margarida de Navarra, ambos escritores franceses do século XVI, Febvre aborda as grandes questões religiosas do século. Na verdade, tanto um quanto o outro são personagens da modernidade, época de distanciamento entre a Igreja, como instituição e Deus. A Igreja, assim, deixa de ser a intermediação entre Deus e os homens, o que permite aos homens manterem a sua fé e "dar as costas" aos representantes da Igreja.

"O impulso religioso não morre, (...) mas é transferido da cena oficial para dentro do ser humano. A religião transforma-se numa questão privada" ${ }^{11}$.

Ao relatar a modernidade, nota-se a preocupação de Febvre em detectar as transformações sociais do final da Idade Média, que induziram os homens a se modificarem. A reação mental, estudada por Febyre, é uma resposta que o

10 FEBVRE, L. Op. cit., p. 225.

11 HELlER, Agnes. O Homem do Renascimento. Lisboa: Editorial Presença, 1982. p.58. 
indivíduo dá ao declínio de um sistema de mundo, que se tornara insuficiente, como também, à difícil reconstrução de um novo. Através da pesquisa na obra de Rabelais, vê-se que o ideal religioso da cristandade prossegue seu processo paulatino de deterioração durante o Renascimento, dando lugar a uma visão de mundo, que se afasta lentamente das regras medievais de comportamento e se aproxima da visão pragmática de um mercador ${ }^{12}$.

E a descrença é o ponto de partida para uma reflexão mais ampla sobre Rabelais e seu tempo. Febvre empreende um minucioso estudo na obra do escritor, tentando captar o sentimento religioso de um homem, considerado por muitos estudiosos e analistas do século XVI como descrente. O trabalho do historiador consiste em uma pesquisa exaustiva sobre François Rabelais, não repetindo o que exegetas do Renascimento já produziram, mas levantando questões. Pois, como ele mesmo disse, "o historiador não é aquele que sabe. É aquele que procura ${ }^{13}$.

Febvre organiza seu livro em duas partes, sendo a primeira destinada a reunir as análises de estudiosos da obra "rabelaisiènne", trabalhando vários aspectos que fizeram com que o autor de Gargantua fosse considerado um grande herege e logo um descrente. Na segunda parte, se volta à outra face de Rabelais, revelando o quanto seu pensamento está impregnado das questóes religiosas do século XVI.

Vale dizer que a primeira parte consiste em um enorme compêndio de escritos sobre a obra de Rabelais, reunindo contemporâneos do século XVI: poetas, polemistas e teólogos, a fim de analisar, através deles, a capacidade, ou a possibilidade, do escritor ser um livro pensador. Além disso, reúne vários estudos sobre o escritor, desde meados do século XVI até o século XX. Trata-se

12 LE GOFF, J.. Para um novo conceito de Idade Média. Lisboa: Imprensa Universitária e editorial Estampa, 1980. p. 43-60.

13 Eis af um exemplo de intelectual inquieto em relação ao conhecimento, que tenta ampliá-lo ao invés de ver no passado modelos prontos e anacrônicos. Febvre se recusa a conceber uma especulação, porque "cada época fabrica mentalmente seu universo. Ela nâo se fabrica somente com todos os materiais que ela dispõe, todos os fatos (verdadeiros ou falsos) por ela herdados ou que ela recentemente adquiriu. A época o fabrica com o que ela tem de próprio, sua ingenuidade especifica, suas qualidades, seus dons e suas curiosidades, tudo que a distingue das épocas precedentes". FEBVRE, L. Le Problème de L'Incroyance du 16 siecle. Paris: A. Michel, 1974, p.11-12. 
portanto de um trabalho de extrema erudição, mas que não possui o mesmo caráter dos realizados pelos historiadores positivistas do século $\mathrm{XIX}^{14}$.

A conclusão de Febvre nos revela os limites desses relatos, quando erroneamente pensam Rabelais como um homem descrente, avesso a qualquer sentimento religioso. $O$ veredito destas testemunhas vê sempre no escritor ateu, um homem que zomba da fé cristã e que se constitui por isso numa ameaça à Cristandade.

Em seguida, Febvre passa a interrogar Rabelais através de sua obra. Surge, então, um homem quieto, um perseguidor da verdade. Nesta primeira parte do livro, como em quase toda a obra, Febvre combate a visão de Abel Lefranc, estudioso da obra "rabelaisiènne" do início do século XX, que pensa Rabelais como descrente. Vê-se também uma grande análise teológica, observando sempre a analogia entre os personagens de Gargantua e Pantagruel, em situações burlescas e a tradição cristã. Há uma expressa intenção do autor em caricaturar, ou melhor, imitar de maneira jocosa algumas passagens da Bíblia. Enfim, o historiador enumera os indícios que levaram muitos estudiosos a conceber Rabelais como um descrente.

A segunda parte que, a principio, é novamente uma análise teológica da obra de Rabelais, procura demonstrar o quanto o seu pensamento era atrelado à existência de Deus. Há uma verdadeira discussão teológica e filosófica em sua obra, que pode ser perfeitamente vinculada ao pensamento religioso de Lutero e Erasmo. $\mathrm{O}$ que se chamou de descrença não passava de duras críticas, irônicas em sua maioria, em uma época de enorme crise religiosa. Tendência que pode ser verificada tanto em Erasmo quanto em Lutero, cada qual à sua maneira. Com essa constatação, o historiador se contrapõe à idéia da descrença e concebe Rabelais como um singular crítico da Igreja do século da Reforma.

Dando continuidade ao estudo, há ainda a intenção de Febvre de constatar a impossibilidade, ou melhor, a dificuldade de se desenvolver um pensamento que fosse autônomo em relação à herança cristã. Sua análise parte de um inventário instigante de detalhes sobre a vida cotidiana, sobre o pensamento filosófico renascentista, além de fazer uma comparação entre o desenvolvimento

14 Os documentos que utiliza não têm em si o conhecimento, seu enorme compêndio serve de base para uma análise crítica. A eruđição, assim, não é o ponto de chegada, mas a condiçäo inicial de trabalho. 
científico e a difusão de práticas místicas e do ocultismo, ambas presentes no homem do Renascimento. Tudo isso a fim de recompor a época estudada sobretudo o material mental disponível e verificar a possibilidade da existência de um livre pensador. (Questão que será amplamente abordada mais adiante).

Assim como o Problema da Descrença, o outro livro de Lucien Febvre, Autour de L'Heptaméron (Em torno do Heptaméron) ${ }^{15}$, também se volta ao problema da religiosidade. Heptaméron é o nome de um livro escrito por Margarida de Navarra, obra onde são relatadas pequenas histórias (setenta ao todo) de carater profano, que é considerado o Decameron francês. Sua importância, na análise de Febvre, está ligada à ambigüidade aparente que envolve Marguerite, que escreve uma obra mundana, imoral para a época, e, ao mesmo tempo, um livro profundamente católico e amplamente conhecido como tal. Em torno do Heptaméron é dividido em duas partes: a primeira dedicada à Marguerite católica, a segunda à Marguerite que escreveu o Heptaméron.

Ao analisar a Marguerite católica, o historiador relata factualmente a vida da personagem, de origem nobre, porém de um ramo menor, até que repentinamente seu irmão sobe ao trono de França. Com Francisco I no poder, a vida de Marguerite muda profudamente; ela passa a ser uma grande aliada do rei de França, ocupando uma posição que é algo entre diplomata e espiã. Através do contato com a nobreza européia, Marguerite termina por casar com o rei de Navarra. Em seguida, Febvre ressalta a formação católica de Marguerite a partir de algumas poesias, e, dedica ainda dois capítulos do livro às possíveis influências da ortodoxia cristã e dos pensadores da Reforma em sua obra poética.

A segunda parte, entitulada "Marguerite que fez o Heptaméron", é destinada a estudar a obra profana que escandalizou a Igreja da época. Alguns setores da intelectualidade francesa chegaram mesmo a negar a autoria de Marguerite. Febvre, no entanto, não vê nenhuma contradição entre Marguerite católica e Marguerite profana. Em Heptaméron, aparecem os mesmos elementos cristãos encontrados na poesia sacra da rainha de Navarra. Finalizando, o estudo conclui que não se pode pensar na perda de religiosidade de Marguerite ao escrever uma obra profana; ao contrário, sua ambigüidade _ ser religiosa e ao mesmo tempo mundana - é uma característica do século XVI, época de crise de 
valores, onde convivem o fervor das crenças e as querelas entre a religião e a vida profana.

Pelo que acabamos de relatar, torna-se evidente o quanto a literatura pode ser útil ao historiador. A Arte em sí é uma das grandes heranças deixada pelo homem e Lucien Febvre, em suas pesquisas, mostra o quanto é sensível às artes, essa grande tradutora e acumuladora de vivências humanas. Falando sobre arte, há uma passagem de R. Mezan, citando Hermann Broch, que traduz muito bem o legado da arte para a História:

"Uma obra de arte 'verdadeira', afirma ele, consiste na materialização, conforme o meio de expressão escolhido, do "sentido da época", apreendido pelo artista em virtude de uma visão intuitiva que lhe permite captar a época como totalidade, acima e através da multiplicidade desorientadora dos acontecimentos que se sucedem e coexistem. Ora, uma obra de arte que reproduz o conteúdo total de uma época (e portanto não apenas o seu estilo), e que representa por isso uma 'novidade' inquietante, não se torna geralmente, algo familiar antes que a época tenha acabado, o que significa que ela é apreciada e reconhecida apenas quando o período da sua criação já se tornou uma totalidade histórica" ${ }^{16}$.

A observação de Broch é pertinente com relação às obras de Rabelais e Marguerite. A percepção de ambos os artistas da totalidade de seu tempo, da complexidade do século XVI, impediu por muito tempo uma compreensão mais profunda de suas obras, o que provocou uma série de especulações que hoje são tidas como sem fundamento. E foi esta "multiplicidade desorientadora dos acontecimentos" o grande trunfo para a realização dos estudos de Febvre. Seus dois livros objetivaram delinear a totalidade histórica, procedimento indispensável à compreensão da obra de Rabelais e Marguerite.

16 MEZAN, R.. Freud, Pensador da C'ultura. $3^{\text {a }}$ ed.. Sâo Paulo: Brasiliense, 1985. p. 27.0 grifo é meu. 


\section{Outillage Mental}

Utensilagem ${ }^{17}$ mental é:

"inventariar em detalhes e depois recompor, para a época estudada, o material mental de que dispunham os homens desta época; através de um esforço de erudição, mas também de imaginação, reconstruir o universo, físico, intelectual, moral, no meio do qual se moveram as gerações que o precederam; tornar evidente, de um lado, a insuficiência das noções de fato sobre tal ou tal ponto; por outro lado, o estudo da natureza engendraria necessariamente lacunas e deformações nas representações que certa coletividade histórica forjaria do mundo, da vida, da religião, da política" ${ }^{18}$.

Partindo destas considerações, Febvre constroe sua história das mentalidades. A recomposição da vida, em seus mínimos detalhes, exige do historiador uma posição aberta face ao conhecimento, ou melhor, torna-se indispensável o combate "contra o espírito de especialização", contra uma história de nomes e datas, em favor de uma "história viva e pulsante". Deste modo, pensar em história das mentalidades é conceber a não-existência de um limite rígido entre etnologia, linguística, sociologia, psicologia, filosofia e história; é tentar fazer da história o ponto de convergência de todas essas visões. A noção de interdisciplinariedade é fundamental à compreensão da concepção de história em Febvre; segundo ele, a história não seria uma ciência, mas um estudo cientificamente conduzido; por isso, a importância de procurar o apoio das outras disciplinas. Dito isso, vale retornar à produção historiográfica do fundador dos Annales e analisá-las a partir deste trecho, ou citação. Assim fazendo, percebe-se o quanto sua obra gira em torno destas indicações e o quanto é possível aprender com elas.

Já foi dito que a problemática de Febvre se prende à relação indivíduo-sociedade. Pois bem, seu conceito de utensilagem mental também se prenderá a essa questão. Através do indivíduo, seja Marguerite, seja Rabelais, o

17 A tradução de outillage comumente se faz para instrumental, ferramentas; entretanto, preferi empregar utensilagem, palavra mais comum em Portugal, mas que se mostrou mais adequada por ter sentido de conjunto, dado pelo sufixo agem Grande Enciclopédia Portuguesa e Brasileira. Lisboa: Enciclopédia Edl. Ltda., v. XXXIII, 1960.

FEBVRE, L.. Combats pour l'Histoire. p. 218. 
historiador entra em contato com a sociedade européia do século XVI. Homens divididos entre o transcendental e a vida terrestre; entre a cristandade e a herança greco-latina, entre o sagrado e o profano. Centra seu foco de atenção nos personagens Rabelais e Marguerite, a fim de buscar em seus mundos, o substrato das idéias renascentistas. É interessante notar que o historiador parte do específico - o indivíduo - para alcançar o genérico e a partir do geral explicar o comportamento do indivíduo. Febvre, então tenta compreender a sociedade francesa do século XVI, para saber o porque da crença ou da descrença. $O$ movimento indivíduo-sociedade-indivíduo, que chamo de "circuito febvreano", está profundamente imbuído da idéia de utensilagem mental, complexo de relações entre o particular e o social que dá origem às idéias e às mentalidades.

O primeiro passo no "circuito febvreano" é analisar o indivíduo, da maneira como se explicou anteriormente. Seu objetivo é percebê-lo a partir de suas temáticas, de suas dúvidas, questionamentos, certezas e ambiguidades, captando o mental através da crença, da fé cristã. A percepção do indivíduo não se esgota com a inquirição de seus escritos; é necessário perceber a influência externa formando, ou mesmo possibilitando a criação de idéias. Com isso, torna-se indispensável ao estudo das mentalidades toda e qualquer forma de difusão de conhecimento, que atue sobre o indivíduo, possibilitando sua integração ao meio. Vê-se que Febvre teve este cuidado ao analisar a formação intelectual de Marguerite, explicitando nela as possíveis influências de Erasmo, da ortodoxia cristã e dos pensadores da Reforma.

Enfim, Febvre tenta esgotar os detalhes que o ajudarão a compreender a problemática deste indivíduo, como também o auxiliarão a perceber a vinculação do indivíduo ao social.

Analisando a sociedade, o historiador aborda a dominação religiosa sobre a vida quotidiana. Através de uma narrativa belíssima, Febvre nos leva à vida de um homem, ou dos homens do Séc. XVI, ou do fim da Idade Média. Realiza aqui uma verdadeira pesquisa etnográfica, onde fala do nascimento e da morte, do tempo marcado pelos sinos das igrejas, ritos e proibições no ato de comer, vida privada, atividade profissional, instrução, casamento, etc... Sua investigação não parte da suposição de que haveria espaço para uma possível ruptura com o pensamento cristão, ou se o rompimento poderia ser tranquilo, mas sim se haveria condições para a existência de um livre pensador. E conclui reafirmando:

"o domínio, mais uma vez, da pressão insidiosa e total da religião sobre os homens. Porque tudo isso se faz sem pensar. Sem 
R. História, São Paulo, n. 122, p. 97-115, jan/jul. 1990.

ninguém se perguntar se pode ou se deve agir de outro modo. A vida é assim mesmo. Pertence à memória dos homens" ${ }^{19}$.

A etnografia "pertence" ao território do antropólogo; contudo Lévi-Strauss, em Antropologia Estrutural, nos fala do paralelismo metodológico entre etnografia e história. O reconhecimento deste tipo de dados se torna possível na busca do inconsciente, dos costumes e práticas que são executados maquinalmente, sem se pensar na sua existência, na sua razão de ser. Age pelo hábito, pela vontade inconsciente de manter os costumes, ou mesmo, pela impossibilidade dada pelo real de se pensar e agir diferente dos outros.

Discordo de Lévi-Strauss, no entanto, quando esquematicamente separa o campo de análise do historiador e o território do etnólogo, cabendo ao primeiro as expressões conscientes e ao outro as condições inconscientes da vida social. E me pergunto: Como é possível separar consciente do inconsciente, ação e reflexo, quando se buscam as mentalidades?

Em seguida, Febvre dirige sua análise para o intricado mundo da palavra e deixa, em parte, a vida social, o dia-a-dia, envolvendo-se na interpretação dos signos, prosseguindo sua pesquisa em direção ao social e ao conjunto de "ferramentas" que compõe a utensilagem mental do período.

Franz Boas nos diz que:

"a diferença essencial entre fenômeno linguístico e outros fenômenos culturais é que os primeiros jamais emergem à consciência clara, ao passo que os segundos, se bem que tendo a mesma origem inconsciente, se elevam frequentemente até o nível do pensamento consciente, produzindo assim raciocínios secundários e reinterpretações" 20 .

19 FEBVRE, L.. Le probleme... . p.322-3. Neste trecho Febvre está se referindo ao inconsciente, categoria introduzida por Marcel Mauss (e Boas) em Ciências Sociais que veio resolver a antinomia de Durkheim entre o empirismo (social como objeto) e os fundamentos kantianos. LEVI-STRAUSS, C.. Op. cit., idem. Vale dizer que L. Febvre não faz nenhuma menção a M. Mauss quando se volta ao estudo do inconsciente. Qual seria a razẫo deste silêncio? Lévi-Strauss nos dá algumas pistas.

20 Apud LEVI-STRAUSS, C.. Antropologia Estrutural. $2^{\mathrm{a}}$ ed.. Rio de Janeiro: Tempo Brasileiro, 1985. p. 35. (O conceito de inconsciente até agora utilizado é do tipo acumulativo e nåo o Inconsciente estrutural). 
Tal afirmação nos leva cada vez mais, a valorizar o estudo lingüístico, como um caminho seguro para se perceber o inconsciente social e sobretudo, para apreender os limites ou parâmetros de formulação dos pensamentos. A língua, assim, torna-se "camisa de força", como diria Roland Barthes, que funciona padronizando emoções, valores, homens. Pensar o impensável é tarefa quase impossível devido à língua, os códigos previamente estipulados pelo social. Será a transformação da organização da sociedade que possibilitará o aparecimento de signos novos e, logo, de um outro modo de pensar. Com isso, o estudo do campo lingüístico se torna indispensável à história das mentalidades, pois a forma mental e a língua correm paralelamente. E é exatamente a correlação que busca Febvre ao analisar o vocabulário do pensamento filosófico renascentista. Sem um inventário sistemático e cronológico de palavras, como entender os meios, de expressão dados ao indivíduo pelo grupo? É impossível conhecer as mentes sem saber de seu vocabulário, sem penetrar nos seus signos. Entrando nesta problemática, Febvre nos demonstra a impossibilidade da existência de um pensamento desvinculado da fé cristã. No século XVI, os pensadores estudados pelo historiador revelam sempre a ambigüidade de sua época. Por mais que suas concepções de mundo sejam inovadoras e precursoras, não se pode afirmar a existência propriamente dita de um livre pensador.

Torna-se patente a situação, quando constatamos o estado tosco em que ainda se encontravam as línguas neolatinas. Assim, o pensamento da Modernidade, em seu caráter profano, estava prejudicado devido: 1) à utensilagem rudimentar da fala quotidiana; 2) ao pensamento filosófico, que era expresso em latim, língua que apresentava uma forte influência do pensamento teológico da Idade Média. Nem mesmo a literatura greco-latina poderia auxiliar o desenvolvimento de novas formas de pensar, já que não existiam significados equivalentes na língua conhecida pelos sábios renascentistas. Então, pode-se concluir que havia um duplo impedimento dificultando, em muito, o surgimento de novos signos.

Vale acrescentar alguns comentários sobre o tipo de lingüística utilizada por Febvre. Nos Combates, há alusões constantes a Meillet e a Brunot, como também a dialetólogos. Régine Robin analisa o apoiọ lingüístico à história de Febvre e fala do seu desconhecimento dos trabalhos de Saussure, Jacobson e Benveniste. Lévi-Strauss, em sua Estrutura Elementar de Parentesco, 1949, também não acrescentou nenhuma inovação ao seu conhecimento lingüístico. É como se Febvre tivesse perdido, ou não tivesse querido estabelecer contato com 
a produção intelectual ligada ao estruturalismo lingüístico, movimento que começava a se difundir no pós-guerra. As análises de Febvre continuavam a valorizar a origem das noções e sua evolução semântica em diacronia. No entanto:

"É em termos de sincronia e de estrutura que Febvre pensa; tanto é assim que nos encontramos em pleno paradoxo. Febvre não se inspira, de modo nenhum, na lingüística estrutural (...) introduz uma espécie de estudo estrutural não formalizado, sincrônico, da interrelações entre os diversos elementos do todo social... " ${ }^{21}$.

Não é somente a palavra que tem importancia dentro da utensilagem mental. Em Rabelais, a ciência e o ocultismo são também instrumentos a serem analisados. O clima místico pode ser, da mesma maneira, encontrado naquilo que erroneamente se chamaria ciência, pois não se encontrava ainda na sua forma empírica, que é a característica primeira da ciência depois de Galileu. Havia um distanciamento enorme entre o estudo dos homens letrados e a aplicação prática deste legado. Enfim, não havia homens que fizessem a relação entre o estudo acadêmico e sua ação pragmática. Distanciamento que impossibilitava o seu crescimento e a relativização da organização cósmica da Igreja. Também eram incapazes de avançar no conhecimento via herança grega, pois liam o grego a partir do cristianismo. A "ciência" assim, não fornecia a estes homens a possibilidade de serem livres pensadores. Por outro lado, o ocultismo, o culto ao místico, teve grande expansão no final da Idade Média. O declínio do mundo medieval provocou o recuo dos dogmas cristãos e o aparecimento e difusão de inúmeras crendices, que impossibilitaram o surgimento de um pensamento empírico e lógico, situação que afasta a hipótese da Descrença.

"O homem não é prisioneiro da natureza, mas da humanidade. Na presença de fatos naturais, ele pode sempre, ou quase sempre, fazer um escolha. Mas esta escolha é menos uma questão de interesse do que uma questão de ritos, de hábitos, de técnicas. Logo, uma questão social, uma questão de sentimentos. É necessário falar

21 ROBIN, Régine. História e Lingüistica. São Paulo: Cultrix, 1978. p. 73. O grifo é meu. 
RAMINELLI, Ronald. Lucien Febvre no caminho das mentalidades.

da prisão (...) estas verdadeiras muralhas que se chamam de leis dos homens, as paixões coletivas e os controles sociais da humanidade" ${ }^{22}$.

Algumas considerações

o último ponto a ser ressaltado é a possível influência de Marcel Mauss na organização da investigação histórica de Febvre. Sua tentativa de, a partir do indivíduo, abarcar a totalidade da sociedade e das instituições se aproxima muito da de Mauss de "fatos sociais totais".

"Nesses fenômenos sociais totais, como nos propomos chamá-los, exprimem-se, ao mesmo tempo, e de uma só vez, toda espécie de intituições: religiosas, jurídicas e morais" ${ }^{23}$.

Mauss, em seu "Ensaio sobre a Dádiva", utilizou o dom e o contra-dom como instituição capaz de abarcar, a partir dela, a totalidade do real. Nota-se, então, uma possível semelhança entre os fenômenos sociais totais de Mauss e o circuito febvreano. O historiador, por sua vez, elegeu o indivíduo como ponto de partida, ou melhor, "instituição" capaz de fornecer, ao mesmo tempo, uma enormidade de informações (vide utensilagem) e exprimir a complexidade de uma época. Mais precisamente, de delinear o pensamento religioso de um homem e suas possíveis implicações com o social.

Viu-se assim como Febvre buscou no indivíduo o sentimento religioso de uma época. Para isto, introduziu na investigação histórica, o conceito de utensilagem mental e aquilo, que se chamou circuito febvreano, ambos exemplos do caminho singular trilhado pelo historiador para enriquecer e porque não, inaugurar um modo particular de fazer história.

No entanto, apesar do historiador ser considerado o principal organizador dos Annales e o "ancestral" da nova história, a evolução dos estudos de mentalidades não seguiu o caminho por ele introduzido e sim o de $\mathrm{Marc} \mathrm{Bloch}^{24}$.

FEBVRE, L. Apud: GUARIBA NETO, V.T.. Op. cit., p. 284.

MAUSS, M.. Sociologia e Antropologia. São Paulo: Edusp e E.P.U., 1974, v. 2. p. 41.

BURGIERE, A.. La Notion de Mentalité chez Marc Bloch et Lucien Febvre. In: Revue de Synthèse, v. 111-2, jul-dez., p.333-48, 1983. 
Historiadores como Mandrou, Duby, Le Goff, Ariès entre outros, têm, comumente seus enfoques nos fenômenos mentais mais amplos e não no particularismo do indivíduo. Além disto, dificilmente utilizam o conceito de inconsciente coletivo. As explicações para os fenômenos são obtidas a nível consciente como fazia Durkheim. Nem mesmo a recente voga das biografias se aproxima do arcabouço teórico e metodológico empregados por Febvre no L'Incroyance...; os estudos de Duby, Ginzburg, Spence e Darnton ${ }^{25}$, apesar de centrarem sua análises nos indivíduos, não utilizam a noção de circuito febvreano e de inconsciente coletivo. Deste modo, as biografias atuais primam pela tentativa de contextualizar o personagem histórico e se aproximam da abordagem dada por Febvre ao indivíduo em seu livro Martim Lutero: Um $\operatorname{destino}^{26} *$.

ABSTRACT: This essay recovers part of Lucien Febvre's work, focusing particularly on the issue of mentalités. Basically, two works are analyzed: The Problem of Disbelief in the Sixteenth Century and $O n$ the Heptameron, both written in the 1940s. The article seeks to trace the paths taken by the author in delineating a problem, and to find the particularity of his work, wich has to do with the understanding of "man" and his attitudes. It remains important to reflect upon how these questions had been treated before Febvre began his studies, showing what were the legacies or traces that allowed this historian to introduce his mentality perspective to the field of historical knowledge. Hence, I do not wish to say that Lucien Febvre was a pioneer in mentalite history, but rather point out that his trajectory was unique, which is the main theme of this essay.

DUBY, G. Guillermo El Mariscal.'Madrid: Alianza Ed.. 1985; Ginzburg, C. O Queijo e os vermes. São Paulo, Cia. das Letras, 1987; SPENCE, J. O Palácio da Memória de Matteo Ricci. São Paulo, Cia. das Letras, 1987; DARNTON, R., Boemia Literária e Revolução. São Paulo: Cia. das Letras, 1987.

26 FEBVRE, L.. Martin Lutero: un destino. México: F.C.E., 1956. Obra da década de 1920, que nâo possui a sofisticaçấo teórica e metodológica do $L$ 'Incroyance.. .

- Agradeço a colaboração de Laura de Mello e Souza, Guilerme das Neves e de Virgínia Fontes. 